\title{
Woman and Political Communication: Megawati dan Pemimpin Simbolik
}

\author{
Dini Safitri \\ Universitas Negeri Jakarta
}

\begin{abstract}
The involvement of women in politics in Indonesia has fundamental problems, namely the minimal representation of women in public spaces. This is because women have been stigmatized and are positioned in the domestic sphere, taking care of household problems, without being able to develop themselves in the public sphere. In fact, there are already rules about the 30\% quota for women in parliament, but has not yet been realized. When you glance at the historical record and the women's movement toward public spaces, has existed since Indonesia's independence in 1945. Rights of women to choose is basically recognized. However, the position of women in politics, very volatile in Indonesia. It is because the democratic process in Indonesia not through means gradual (gradual) but through jumps (leaps). Each leap democracy will produce political visions different countries and sometimes very dramatic in seeing women's issues. This phenomenon, then bring up the figure of Megawati's Indonesian women representing the highest ever reached peak Indonesian leader. As a leader, Megawati is the symbolic leader. Megawati is symbolic leader who tried to communicate how to obtain the status, prestige and reputasinnya, or in other words, to fulfill the functions and symbols are fused.
\end{abstract}

Key Words: Megawati, Symbolic Leader, Woman and Political Communication

\begin{abstract}
Abstrak
Keterlibatan Perempuan dalam politik di Indonesia mengalami persoalan mendasar, yaitu keterwakilan perempuan yang sangat minim di ruang publik. Hal ini dikarenakan perempuan selalu terstigma dan diposisikan berada dalam ranah domestik, mengurusi masalah rumah tangga, tanpa bisa mengembangkan diri dalam ranah publik. Padahal, sudah ada aturan tentang kuota $30 \%$ perempuan di parlemen, namun belum terealisasi. Bila melirik catatan sejarah perempuan dan gerakan menuju ruang publik, sudah ada sejak kemerdekaan Indonesia pada tahun 1945. Hak perempuan untuk memilih pada dasarnya sudah diakui. Namun, posisi perempuan dalam politik, sangat fluktuatif di Indonesia. Hal itu disebabkan karena proses demokrasi di Indonesia tidak melalui cara-cara bertahap (gradual) tapi melalui lompatan-lompatan (leaps). Setiap lompatan demokrasi akan menghasilkan visi-visi politik negara yang berbeda dan terkadang sangat dramatis dalam melihat persoalan perempuan. Fenomena tersebut, kemudian memunculkan sosok Megawati yang mewakili perempuan Indonesia yang pernah mencapai puncak pemimpin tertinggi Indonesia. Sebagai seorang pemimpin, Megawati adalah pemimpin simbolik. Megawati mewakili sosok pemimpin simbolik yang mencoba mengomunikasikan bagaimana memperoleh status, prestise dan reputasinnya, atau dengan kata lain untuk memenuhi fungsi dan simbol yang menyatu.
\end{abstract}

Kata Kunci : Megawati, Perempuan dan Komunikasi Politik, Pemimpin Simbolik 


\section{Pendahuluan}

Keterlibatan Perempuan dalam politik di Indonesia, menemui persoalan dasar, yaitu persoalan keterwakilan perempuan yang sangat minim di ruang publik. Keterwakilan ini, tidak hanya bisa dilihat dari minimnya jumlah perempuan yang duduk sebagai anggota DPR RI, namun juga partisipasi perempuan dalam politik dan masyarakat. Hal ini terkait erat dengan perosalan budaya di Indonesia, dimana perempuan selalu terstigma dan diposisikan berada dalam ranah domestik, mengurusi masalah rumah tangga, tanpa bisa mengembangkan diri dalam ranah publik. Padahal, dalam kebijakan pemerintah, sudah ada kemajuan yang dicapai, terkait dengan pemberdayaan perempuan di bidang politik, yaitu ditetapkannya
Undang- Undang Nomor 27 Tahun 2007 tentang Komisi Pemilihan Umum (KPU), Undang-Undang Nomor 2 Tahun 2008 tentang Partai Politik, disusul dengan Undang-Undang Nomor 10 Tahun 2008 tentang Pemilihan Umum Anggota Dewan Perwakilan Rakyat, Dewan Perwakilan Daerah, dan Dewan Perwakilan Rakyat Daerah.

Undang-Undang tersebut mengamanatkan kuota 30\% keterwakilan perempuan dalam kepengurusan partai politik di tingkat pusat dan daerah dalam daftar yang diajukan untuk calon anggota legislatif. Namun faktanya, UU tersebut belum terealisasi. Berikut data Rekapitulasi Keterwakilan Perempuan di DPR RI 2009-2014:

\section{Tabel 1. Jumlah dan Prosentase Anggota Legislatif Perempuan di DPR RI 2009-2014}

\begin{tabular}{|l|c|c|}
\hline Jenis Kelamin & Jumlah & Prosentase (\%) \\
\hline Perempuan & 99 orang & 17,68 \\
\hline Laki-Laki & 461 orang & 82,32 \\
\hline
\end{tabular}

Sumber: Situs Resmi DPR RI http://www.dpr.go.id. diakses tanggal 3 JUNI 2014

Berdasarkan tabel jumlah dan prosentase anggota legislatif perempuan di DPR RI diatas, terlihat dominasi lakilaki di parlemen. Hal ini menunjukan adanya distribusi kekuasaan yang tidak seimbang. Penyebabnya adalah secara sosial dan budaya, dominasi tersebut terjadi karena kekuasaan laki-laki didukung oleh sistem patriakal yang menguasai paradigma dunia. Akibatnya, pemahaman dan perlakuan diskriminatif serta ketidakadilan atas perempuan, kekal dengan berbagai bentuk. Terkadang paradigma patriakal tersebut, tanpa sadar didukung oleh perempuan sendiri.

$\begin{array}{llr}\text { Pemahaman } & \text { patriarki yang } & \begin{array}{c}\text { sudah } \\ \text { ada dalam }\end{array} \\ \text { paradigma } & \text { dunia, } \\ \text { menyebabkan } & \text { konstruksi } & \text { tentang }\end{array}$

perempuan menjadi diskriminatif dan menguntungkan laki-laki. Menurut Gaffar (2001: 4), konstruksi sosial, membutakan perempuan dan tidak memungkinkan mereka untuk berperan secara aktif dalam politik. Kekuasaan laki-laki sangat kuat, didukung sistem sosial dan budaya, membuat peran perempuan dalam politik sangat jarang mencapai puncak. Seandainya ada perempuan yang berada dalam posisi puncak, maka lebih banyak karena realitas di luar mereka. Realitas yang membuat perempuan harus keluar dan berontak serta tidak mau hanya sekedar dijadikan instrumen politik. Maka lahirlah gerakan perempuan menuju ruang publik. 
Majunya perempuan ke ruang publik dan menduduki tempat-tempat strategis pengambilan keputusan adalah satu-satunya cara agar kepentingan perempuan terwakili. Tokoh Feminis politik, Mary O Brien (1989:155), pernah mengutarakan, perempuan selama ini, hanya digunakan sebagai alat oleh partai demi alasan pembaharuan dunia (in the name of a vision that transforms the world). Perempuan dijadikan alat politik dan menjadi kaum mayoritas yang inferior dan terbungkam (silenced and thwarted majority). Lahirnya gerakan perempuan untuk memulihkan hak-hak politiknya, erat kaitannya dengan proses transformasi sosial yang identik dengan transformasi demokrasi. Tujuannya adalah untuk menciptakan suatu hubungan antar sesama manusia yang secara fundamental baru, lebih adil, dan saling menghargai. Berikut ini adalah gambaran tujuan gerakan perempuan ke ruang publik:

\section{Gambar 2. Wilayah Kebebasan Perempuan}
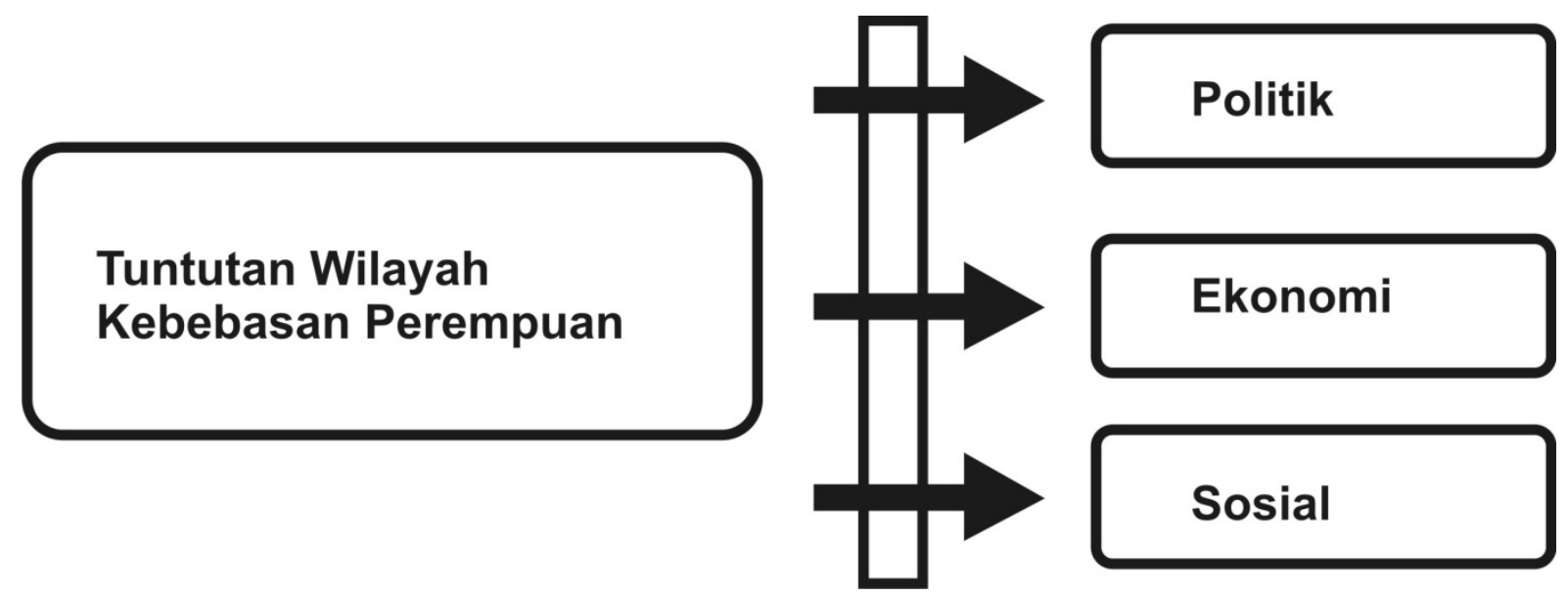

(http://filsufgaul.wordpress.com/2012/o3/11/perempuan-dan-politik-di-indonesia/)

Berdasarkan gambar diatas, kita mendapat gambaran mengenai peran ideal perempuan dalam politik. Perempuan di seluruh dunia berkeinginan untuk mempengaruhi keputusan-keputusan yang menyangkut keluarga, perekonomian, masyarakat, negara, serta struktur hubungan internasional. Mereka berangkat dari sebuah kesadaran bahwa apa yang terjadi dalam dirinya, pikiran serta tubuhnya, tidak pernah lepas dari urusan politik. Hal ini merupakan usaha kemanusiaan agar semua masyarakat, laki-laki dan perempuan, dari segala ras, etnis, bangsa, dan agama dapat menikmati hak asasinya. Walaupun begitu, ada saja faktor budaya, sistem sosial, sistem politik, hingga masalah kemiskinan menjadi jurang yang sangat sulit dilalui perempuan. Sebagai contoh adalah kasus Indonesia.

Sejak kemerdekaan Indonesia pada tahun 1945, hak perempuan untuk memilih pada dasarnya sudah diakui. Namun, posisi perempuan dalam politik, sangat fluktuatif. Menurut Blackburn (2004:94), hal itu disebabkan, karena proses demokrasi di Indonesia tidak melalui cara-cara bertahap (gradual) tapi melalui lompatan-lompatan (leaps). Setiap lompatan demokrakrasi, akan menghasilkan visi-visi politik negara yang berbeda, dan terkadang sangat dramatis, dalam melihat persoalan perempuan. Berbagai solusi sudah banya ditawarkan, seperti memperkuat sistem politik dengan 
konstitusi dan aturan hukum yang berpihak pada perempuan. Namun dengan keterwakilan perempuan yang hanya $17 \%$ di parlemen, mampukah mereka memperkuat sistem? Nyatanya selama 5 tahun kemarin, tidak banyak yang bisa dilakukan.

Namun ada cerita menarik dalam pemilu 2014 ini, yaitu kemunculan sosok Megawati yang kerap mewarnai pemberitaan pemilu. Bukan sebagai capres, seperti lima atau sepuluh tahun sebelumnya, namun sebagai seorang "ibu" yang berkuasa terhadap salah satu capres yang diusung dari PDIP. Keterwakilan Megawati dalam cerita pemilu 2014, menarik untuk dikaji. Mengingat, Megawati pernah menduduki posisi puncak dalam pemerintahan, kemudian ikut berpartisipasi dalam pemilu untuk bisa kembali duduk di posisi puncak tersebut, walau gagal dan gagal. Tapi kemudian, tampil menjadi sosok "ibu super power" atas capres yang diusung partainya. Keterwakilan perempuan di ruang publik, pada sosok Megawati, yang pernah berkuasa sebagai presiden, dan kini "berkuasa" atas capres yang diusungnya, menjadikan sosok Megawati sebagai pemimpin simbolik.

Pemimpin simbolik menurut Klapp (1964), adalah pemimpin yang mencoba mengkomunikasikan bagaimana ia memperoleh STATUS, PRESTISE \& REPUTASI, atau dengan kata lain untuk memenuhi fungsi dan simbol yang menyatu (Sapir, 1930). Dan, Megawati dalam berbagai kesempatan, selalu mengomunikasikan bahwa ia adalah anak presiden, yang sejak kecil sudah hidup di istana, dan sampai saat ini kehidupannya tetap seperti itu, seorang pimpinan partai, yang mempunyai kekuasaan yang sangat besar. Berdasarkan fenomena tersebut, saya tertarik untuk menelaah bagaimana Megawati bisa tampil menjadi fenomena pemimpin simbolik.

\section{Tinjauan Pustaka}

Menurut Oxford English Dictionary, Helliwel dan Hindes (dalam Taylor, edt. 1999: 73), terdapat beberapa makna tentang kata kekuasaan. Pertama, kekuasaan adalah memiliki kontrol dan kekuatan memerintah terhadap pihak lain. Para sosiologis memahami kekuasaan sebagai kapasitas untuk mendapatkan pihak lain, melakukan apa yang diharapkan, atau diminta dilakukan.

Kedua, kekuasaan adalah kemampuan yang legal, kapasitas atau kewenangan untuk bertindak, khususnya pada proses mendelegasikan kewenangan. Kekuasaan dalam pemahaman ini, merujuk pada kewenangan atau hak yang oleh sebahagian orang, mendapatkan pihak lain, melakukan segala, yang mereka anggap sebagai wewenang.

Ketiga, kekuasan adalah kemampuan untuk melakukan atau mempengaruhi sesuatu atau apapun. Kekuasaan dalam konsteks ini, berhubungan dengan agency, yaitu kekuasaan merupakan kemampuan seseorang untuk melakukan perubahan/ perbedaan di dunia. (Taylor, 1997: 73).

Menurut Salami (1981), kekuasaan adalah cara membina hubunganhubungan antara masyarakat awam dan masyarakat politik. Kekuasaan harus membawa kesejahteraan bagi masyarakat awam dan bukan mendatangkan dominasi yang mengakibatkan ketidakadilan dan diskriminasi politik bagi masyarakat awam. Namun, jika terjadi kekerasan, ketidakadilan, dan diskriminasi pada masyarakat awam, yang disebabkan hegemoni kelompok penguasa dan kaum borjuis termasuk kaum intelektual, maka Gramsci dalam konsep hegemoninya, mengatakan akan selalu ada kekuataan yang dipergunakan, untuk melawan tekanan dan sikap represif. Dipercayai juga, akan ada cara-cara politik yang kreatif dan cerdas dari kelompok- 
kelompok masyarakat, yang tidak mau menerima hegemoni ideologi yang menindas.

Menurut Gramsci (dalam Simon, 1999), kekuasaan tidak hanya diperoleh dan dipertahankan dengan cara kekerasaan, namun dapat diperoleh dan dipertahankan dengan cara soft, yang disebutnya dengan hegemoni. Kelompok yang selama ini dianggap subordinat penguasa, atau bahkan menentang penguasa, dapat membangun aliansi baru, guna menciptakan hegemoni baru. Kelas dominan, sebagaimana pemahaman Marxis, yang dipergunakan untuk menjelaskan relasi kekuasaan di masyarakat borjuis, adalah kelompok dominan yang menggunakan hegemoni negara dan sumber daya ekonomi serta produksi, yang berakibat, terjadinya subordinasi kekuasaan dan sumber daya ekonomi dan produksi bagi kelas pekerja.

Gerakan perempuan ke ruang publik dimaksudkan agar keterwakilan perempuan dalam hal kekuasaan, menjadikan perempuan berani bicara untuk menyatakan dan memperdebatkan apa yang mereka inginkan dan harapkan terjadi. Dalam konteks ini, diperlukan kemampuan perempuan untuk mengoptimalkan kekuatan bahasa dalam mengkonstruksi realitas, sebagaimana dinyatakan oleh Castell (1983: 359), kekuasaan sampai kapanpun, tetap merupakan aturan sosial yang membentuk dan mendominasi kehidupan sosial itu sendiri.

Lebih lanjut Westwood (2002:5) menegaskan, kekuasaan adalah arsitek dunia sosial. Kekuasaan yang merancang kesesuaian peranan dalam interaksi dan struktur sosial. Atas alasan tersebut, maka perempuan harus memiliki kekuasaan dan kesempatan menjalankan kekuasaan, sehingga dapat memperoleh pemahaman yang sama dan kekuasaan yang seimbang dengan laki-laki. Dalam keterwakilan tersebut, Megawati sudah mampu untuk merancang kesesuian peranan perempuan sebagai pemimpin, pada posisi keperempuannya, yaitu sosok "ibu". Perlu digaris bawahi, posisi ibu, juga pemimpin dalam rumah tangga. Ia yang mengatur anak-anak, dan hal-hal yang berkenaan dengan urusan rumah tangga. Walaupun, dalam posisi kepemimpinan, ibu, adalah sosok wakil dari bapak. Sebagai wakil, tetap memiliki kekuasaan dan wewenang. Hal inilah yang akan ditelaah dalam analisa dan interpretasi, bagaimana Megawati bisa tampil menjadi fenomena pemimpin simbolik.

\section{Metode}

Metode yang digunakan adalah kualitatif yang memfokuskan pada penelitian studi kasus (case study). Studi kasus adalah sebuah strategi penelitian yang mengacu pada -bentuk pertanyaan mengapa dan bagaimana. Peneliti tidak mengontrol peristiwa yang diteliti, namun fokus pada fenomena kontemporer dalam beberapa konteks kehidupan. Menurut Yin dalam bukunya Case Study Desing and Method (1989: 13), strategi penelitian studi kasus, dipakai untuk menguji peristiwa kontemporer yang berkaitan dengan prilaku, dan hampir tidak dapat dimanipulasi fakta yang ada.

Penelitian ini menfokuskan pada pertanyaan penelitian, bagaimana dan mengapa keadaan atau realitas tersebut dapat berlangsung, apa sebenarnya yang menjadi persoalan yang sesungguhnya, serta bagaimana menjelaskan keadaan yang dialami Megawati. Unit analisis penelitian ini Megawati sebagai pemimpin simbolik. Objek penelitian adalah tulisan di media massa yang menuliskan Megawati sebagai narasumber, baik ditulis secara langsung dalam kutipan wawancara atau dalam kutipan tidak langsung. Sumber data diambil secara acak, tidak dengan penetapan periode waktu tertentu, 
namun secara bertujuan. Dimana berita yang dipilih telah melalui proses seleksi yang berhubungan dengan studi kasus yang diteliti, pemimpin simbolik. Berita yang dipilih mulai dari tahun Megawati terjun ke dunia politik, sampai pada berita politik 2014, yang kerap menampilkan Megawati dan Joko Widodo.

\section{Analisa dan Interpretasi Megawati dan Pemimpin Simbolik}

Menurut Klapp (1964), Pemimpin Simbolik adalah seseorang yang mencoba mengkomunikasikan bagaimana memperoleh STATUS, PRESTISE \& REPUTASI atau dengan kata lain untuk memenuhi fungsi dan simbol yang menyatu. Dalam hal ini Megawati memiliki status sebagai anak kedua Soekarno, presiden pertama Indonesia, dari Fatmawati. Ia dibesarkan dalam suasana keistanaan karena Soekarno menjabat sebagai presiden. Sebagai anak presiden, Megawati memiliki prestise, ia bukan "orang biasa".

Tidak hanya status dan prestise yang menjadi keunggulan Megawati. Ia juga berusaha memiliki reputasi sendiri, saat mahasiswa, Megawati berkecimpung di dunia politik melalui GMNI. Setelah itu, karir politik Megawati terus melaju. Tahun 1986, Mega menjadi wakil ketua PDI Cabang Jakarta Pusat. Kemudian, pada 1993, terpilih menjadi Ketua Umum PDI. Namun, Kongres PDI di Medan tahun 1996, memutuskan untuk mengganti Megawat dengan Soerjadi sebagai Ketua Umum PDI.

Megawati pun bereaksi, ia tidak mengakui hasil kongres tersebut. Kemudian, terjadi Peristiwa 27 Juli, yang menewaskan beberapa pendukung Mega. Pada peristiwa itu, pendukung Soerjadi berusaha merebut kantor DPP PDI di Jalan Diponegoro, dari tangan pendukung Mega. Beberapa aktivis ditahan dan dipenjarakan karena kerusuhan tersebut.
Akhirnya PDI terbelah menjadi dua, PDI Soerjadi dan PDI Mega.

Pada Pemillu Tahun 1999, PDI Mega berubah nama menjadi PDI Perjuangan dan berhasil memenangkan pemilu. Sayangnya, walau menjadi pimpinan partai pemenang pemilu, Megawati tidak serta merta menjadi Presiden. Sidang Umum 1999, memutuskan Gus Dur sebagai presiden dan Megawati sebagai wakilnya. Dua tahun kemudian, 23 Juli 2001, mandat MPR RI yang memutuskan Gus Dur sebagai presiden dicabut. Barulah, akhirnya Megawati yang menjadi Presiden.

Masa pemerintahan Megawati berakhir pada tahun 2004, ketika pemilu kembali dilangsungkan. Susilo Bambang Yudhoyono, mantan Menteri Koordinator pada masa pemerintahan Megawati, terpilih menjadi presiden. Sementara Megawati yang mencalonkan diri sebagai capres saat itu, gagal memimpin kembali. Lima tahun kemudian, 2009, Megawati kembali maju sebagai calan presiden, dan gagal lagi. Yang menarik adalah tahun ini, 2014. Sempat sebelumnya diberitakan ingin maju kembali, namun akhirnya Megawati memberikan mandat kepada orang lain untuk maju sebagai capres. Namun langkah politik ini berhasil membuat kekuasaan Mega menjadi lebih besar dari sebelumnya. Dalam hal ini media, mulai dari radio, televisi, koran sampai media baru, membentuk panggung yang luas, dimana drama publik diputar, menampilkan Megawati sebagai pimpinan simbolik. Respon khalayak atas drama ini juga luar biasa, dengan beragam komentar. Terjadi "perang iklim" opini publik dalam mempengaruhi khalayak untuk memilih calon pemimpinnya.

Capres yang diusung Megawati, adalah capres yang juga tidak kalah simbolisnya, dimana jauh sebelumnya, ia tak dikenal. Sampai kemudian, maju sebagai gubernur DKI Jakarata, kemudian 
menjadi pemimpin simbolis yang membuat khalayak mengangap ia adalah sosok orang baik, seperti "pahlawan". Namun, dalam perjalanan menuju capres ini, penggambaran capres yang diusung Megawati ini, tidak selalu dalam penggambaran baik, terselip opini negatif. Hal ini terkait dengan apa yang ditulis Klapp (1964), drama publik dan implikasinya terhadap perubahan, yaitu fenomena ketidakstabilan opini publik dalam masyarakat modern.

Lebih lanjut Klapp juga mengatakan, pemimpin simbolik adalah analisis probing dan provokatif dari proses drama publik dan aktor, yang memainkan peran utama, dibahas dari segi signifikansi mereka untuk struktur yang berubah dengan cepat masyarakat. Diilustrasikan oleh Klap sebagai sejarah kasus hidup, bagaimana organisasi sosial dapat menciptakan citra publik dengan beragam komentar yang menarik dan pemikiran pada kehidupan publik dalam masyarakat.

Berdasarkan gambaran Klapp diatas, maka hasil temuan interpretasi terhadap analisa Megawati sebagai Pemimpin Simbolik adalah sebagai berikut:

1. Seseorang dapat dikatakan pimpinan simbolik, jika ia adalah pimpinan dari suatu organisasi politik yang duduk dan memiliki kewenangan formal, seperti mereka yang memegang jabatan publik. Ia juga memiliki latar belakang sosial tertentu dengan polapola pengakaderannya, dan peran dari komunikatornya sendiri.

Dalam hal ini, Megawati memiliki jabatan publik sebagai Ketua Umum PDIP. Ia memiliki latar belakang sosial sebagai anak dari Soekarno, proklamator dan presiden RI. Saat menjadi mahasiswa, Megawati sudah mulai terjun ke politik dengan terjun di GMNI, dan kemudian menjadi pengurus PDI, sampai kemudia terpilih menjadi ketua umum PDI yang kemudian menjadi PDIP karena terjadi konflik internal. Dalam hal ini, Megawati mengikuti pola pengkaderan sebelum menjadi ketua umum. Kemudian, setelah menjadi ketua umum, Megawati kemudian mengader kader-kader lain untuk bisa tampil menjadi pemimpin simbolik. Salah satunya adalah Megawati memberikan mandat kepada Joko Widodo untuk maju sebagai capres dalam pemilu 2014.

Sebagai seorang komunikator politik dan aktor politik, Megawati sudah menunjukan reputasinya sebagai Presiden RI ke 5, Ketua Umum PDIP, dan pernah dianugerahi oleh Majalah Fortes dalam edisi 4 September 2004, sebagai nomor 8 dari 100 perempuan, terkuat di dunia. Megawati di sejajarkan dengan perempuan-perempuan kelas dunia, seperti Sonia Gandhi (India) urutan ketiga, Presiden Filipina Gloria Arroyo (9), Perdana Menteri Banglades Begum Khaleda Zia (14), Presiden Sri Lanka Chandrika Kumaratunga (44), pemimpin oposisi Myanmar Aung San Suu Kyi (45) dan Mantan Perdana Menteri Inggris Margareth Thatcher (21).

2. Menurut R. Dahl \& CE Lindblom (1953), pemimpin simbolis adalah mereka yang merupakan suatu Interest Group (Kelompok Kepentingan) yang khusus sifatnya, yaitu: memiliki sifat persaingan yang kuat, memegang suatu dominasi tertentu didalam menentukan suatu kebijakan. Dalam hal ini, Megawati memimpin PDIP, sebagai interest group, yaitu parpol yang memiliki sifat persaingan yang kuat, dengan lawan politiknya dalam pilpres 2014 . Seperti diketahui, pada pemilu 2014 kali ini, PDIP berhasil tampil kembali, 
menjadi partai yang memperoleh suara terbanyak, setelah sebelumnya direbut oleh Partai Demokrat. Namun, perolehan tersebut, tidak cukup signifikan untuk bisa mengajukan capres sendiri. Dalam hal ini, Megawati yang memiliki power untuk memilih capres dan cawapres yang akan maju dalam pilpres 2014, maka terpilihlah mandat diberikan kepada Jokowi dan JK. Kedua orang ini, menghadapi persaingan yang kuat dengan satu pasangan lawan mereka, Prabowo dan Hatta Rajasa.

3. Menurut J. Rosenau (1963), kepemimpinan politik sebagai kelompok kepentingan, dilihat dari bagaimana mereka membentuk suatu pendapat nasional. Hal tersebut terlihat dari faktor: latar belakang sosial, persepsi, cara melakukan evaluasi, dan saluran komunikasi yang digunakan. Dalam Pemilu 2014 ini, Megawati banyak membentuk pendapat nasional, mulai dari pemberian mandat yang dilakukan sebelum pemilihan legislatif (pileg), sampai berkonflik dengan Prabowo, ketua umum gerindra, terkait pemberian mandat tersebut. Dimana Megawati, dinilai sebagai sosok yang berkhianat terhadap perjanjian yang pernah dibuat dengan Prabowo, terkait pilpres 2014. Namun Megawati, maju terus dan tidak mengindahkan opini negatif tersebut. Disinilah terlihat power Megawati untuk bisa mengindahkan segala tudingan tersebut, dengan membuat opini balasan di media. Megawati berdalih, dia tidak berkhianat karena perjanjian tersebut tidak sah, karena faktanya tidak terjadi.

Berdasarkan faktor penyebab terjadinya, dimulai dari latar belakang sosial, Megawati pernah menjadi Presiden, dan beberapa kali mencalonkan kembali, namun tidak berhasil. Fakta ini, sempat menjadi pertanyaan publik, akankah Megawati mencalonkan kembali sebagai capres dalam pemilu 2014 ini, ataukah menyerahkan mandat kepada joko widodo yang digadang-gadang media akan menjadi capres dari PDIP. Akhirnya, pilihan mandat, yang dipilih Megawati. Ia pun memberikan surat mandat yang menunjuk Gubernur DKI Jakarta, Joko Widodo (Jokowi), sebagai calon presiden dari partainya dalam akun Twitter resmi @PDI_Perjuangan. Yang kemudian dirilis dan diliput oleh media nasional. Salah satunya seperti yang dikutip dibawah ini:

"Pada, Jumat, 14 Maret 2014, Megawati resmi mendeklarasikan Jokowi sebagai calon presiden.Selain mandat, Megawati juga menginstruksikan tiga perintah harian bagi seluruh elemen Partai Demokrasi Indonesia Perjuangan”.

(tempo.co)

Pilihan mandat tersebut, jauhjauh hari sudah bisa dibaca oleh para pengamat politik. Karena ada citra pemimpin simbolik dalam diri jokowi, yang disimbolkan oleh media. Maka pilihan media, akhirnya menjadi pilihan Megawati, berdasarkan pertim-bangan yang lebih besar, dari sekadar mengajukan diri kembali. Itulah latar belakang Megawati memberikan mandat, berdasarkan persepsi yang ia terima dari media dan orang-oran dekatnya. Darisanalah, Megawati kemudian melakukan evaluasi sebagai dampak positif atau negatif dari keputusan yang diambilnya. Kemudian, keputusan tersebut ditetapkan dan diumumkan melalui media, agar diketahui dan dapat dilaksanakan langkah selanjutnya. 
4. Menurut E.SAPIR (1930), pemimpim simbolik adalah seseorang yang dapat memenuhi suatu fungsi didalam mewujudkan suatu simbol tertentu. Pemberian mandat oleh Megawati, kepada kadernya, menjadikan Megawati sebagai pemberi simbol kepada Joko widodo untuk meneruskan perjuangannya. Simbol ini, menjadikan Megawati sebagai pemimpin simbolik seutuhnya karena dapat mewujudkan dirinya sebagai simbol kekuatan dan kekuasaan yang dapat memberikan mandat. Dan orang lain tidak dapat berlaku demikian, hanya Megawati yang memiliki wewenang untuk memberikannya.

\section{Kesimpulan}

Latar belakang sosial, persepsi, cara melakukan evaluasi, saluran komunikasi yang digunakan adalah empat faktor yang dapat menjelaskan bagaimana Megawati dapat menjadi seorang pemimpin simbolik. Megawati, sebagai ketua umum PDIP, pada pemilu 2014, bersaing kuat dengan partai lainnya, khususnya Gerindra. Walau tampil menjadi partai yang memperoleh suara terbanyak, PDIP pimpinan Megawati tidak cukup signifikan untuk bisa mengajukan capres sendiri. Namun posisi Megawati sebagai pemimpin partai, sangat menentukan dalam proses pemilihan capres dari PDIP. Dan Megawati menentukan untuk memberikan mandat kepada Joko Widodo yang dilakukan sebelum pemilu legislatif. Selain itu, dalam Pemilu kali ini, Megawati banyak membentuk pendapat nasional, terutama perihal pemberian mandat yang berujung konflik dengan Prabowo, Ketua Umum Dewan Pembina Partai Gerindra. Pemberian mandat ini menjadikan Megawati menjadi pemimpin simbolik yang "sesunguhnya". Megawati memberikan simbol kepada Joko widodo untuk meneruskan "perjuangannya".

\section{Daftar Pustaka}

\section{Buku}

Castells, M. 1983. The City and the Grassroots: A Cross-cultural Theory of Urban Social Movements. Berkeley: University of California Press

Ghaffar, Afan dkk. 2001. Potret Perempuan: Tinjauan Politik, Ekonomi dan Hukum di Zaman Orde Baru. Yogyakarta: PSW UMY dengan Pustaka Pelajar.

O'Brien, Mary. 1989. Reproducing the World: Essay in Feminist Theory. Boulder: Westview Press.

Tim Litbang Kompas. 2004. Partai-partai Politik di Indonesia; Ideologi dan Program 2004-2009. Jakarta: Kompas.
Saptono, Irawan dan Lukas Luwarso.1996. Megawati Soekarnoputri; Pantang Surut Melangkah. Jakarta: ISAI.

Klapp, Orrin Edgar. 1964. Symbolic Leaders: Public Dramas and Public Men. USA: Irvington Publisher

Robert Dahl and C.E. Lindblom. 1953. Politics, Economics, and Welfare. New York: Harper and Row

James N. Rosenau, ed., 1963. International Politics and Foreign Policy. New York: Free Press of Glencoe.

Simon, Roger. 1999. Gramcsi’s Political Thought, alih bahasa oleh Kamdani dan Baehaqi, Imam 
Salami, Leonardo. 1981. The Sociology of Political Praxis: An Introduction to Gramsci's Theory. London \& Boston

Sapir, Edward. 1930. Southern Paiute: a Shoshonean Language. Proceedings of the American Society of Arts and Sciences 65. 1-3. (reprinted 1992, The Collected Works of Edward Sapir, ed. by William Blight. Berlin: Mouton de Gruyter)

Taylor, Steve. 1999. Sociology; Issue and Debates. Palgrave Macmillan.

Westwood, Sallie. 2002. Power and The Social. 1 edition. London and New York: Routledge.

\section{Jurnal}

Blackburn, Susan. 2004. Gradualism Versus Democratic Leaps: Political Representation of Women In Australia and Indonesia. Jurnal Perempuan edisi 34. Jakarta: Yayasan Jurnal Perempuan

Messner, Michael A. 2011. Gender Ideologies, Youth, Sports, and the Production of Essentialism Sociology of Sport Journal. Vol. 28: 151-170.
Ridgeway, Cecilia L. 2011. Framed by Gender: How Gender Inequality Persists in the Modern World. NewYork: Oxford.

\section{Online}

http://www.pustaka.ut.ac.id/dev25/pdfpr osiding2/fisip201216.pdf

http://www.ukm.my/jkom/journal/pdf_fi les/2013/V29_1_73-97.pdf

http://www.indiana.edu/ tisj/readers/ful l-text/14-4\%20Stalder.html

http://kepustakaan-presiden.pnri.go.id

http://tokohindonesia.com

http://filsufgaul.wordpress.com/2012/o3 /11/perempuan-dan-politik-diindonesia/

http://profil.merdeka.com/indonesia/m/ megawati-soekarnoputri/

http://pemilu.tempo.co/read/news/2014/ 03/14/269562244/MegawatiTunjukkan-Surat-Mandat-JokowiNyapres

http://www.dpr.go.id. 